\title{
Changes in macular parameters in different types of amblyopia: optical coherence tomography study
}

This article was published in the following Dove Press journal:

Clinical Ophthalmology

4 August 2017

Number of times this article has been viewed

\section{Manal Ali Kasem \\ Amani E Badawi}

Department of Ophthalmology, Faculty of Medicine, Mansoura Ophthalmic Center, Mansoura University, Mansoura, Egypt
Correspondence: Amani E Badawi Department of Ophthalmology, Faculty of Medicine, Mansoura Ophthalmic Center, Mansoura University, Mansoura, 60 Elgomhoria St, Dakahlia Governorate 35516, Egypt

Tel +20 I0 038I 827।

Email amanibadawi37@yahoo.com
Purpose: The purposes of this study were to investigate the changes in macular parameters (thickness, volume) and peripapillary retinal nerve fiber layer (RNFL) thickness (RNFLT) in different cases of amblyopia versus the normal fellow eyes using optical coherence tomography (OCT) and to estimate the relationship of OCT changes with various defined patients' parameters.

Design: This is a prospective, observational, cross-sectional case series.

Methods: The method involved measuring the peripapillary RNFLT, macular thickness, and macular volume via spectral domain (OCT) in different types of amblyopia and comparing with the other fellow eyes. This study was conducted at the Mansoura Ophthalmic Center.

Results: A total of 64 patients with different types of amblyopia were included. The mean central macular thickness (CMT) was $196.2 \pm 50.03 \mu \mathrm{m}$ in the amblyopic eyes versus $167 \pm 12.76 \mu \mathrm{m}$ in the fellow eyes $(P=0.000)$, the mean average macular thickness was $265.80 \pm 12.77 \mu \mathrm{m}$ in the amblyopic eyes versus $259.10 \pm 3.09 \mu \mathrm{m}$ in the fellow eyes $(P=0.000)$, the mean macular volume was $7.59 \pm 0.32 \mathrm{~mm}^{3}$ in the amblyopic eyes versus $7.34 \pm 0.071 \mathrm{~mm}^{3}$ in the fellow eyes $(P=0.002)$, and the mean global RNFLT was $97.00 \pm 11.60 \mu \mathrm{m}$ in the amblyopic eyes versus $78.50 \pm 13.05 \mu \mathrm{m}$ in the fellow eyes $(P=0.029)$. There was a discrepancy between the different amblyopic types. Age and the axial length were the only independent variables that statistically significantly correlated with the CMT.

Conclusion: The unilateral amblyopic eyes were prone to have a higher CMT and thicker global RNFL compared to those of the sound fellow eyes. Retinal variations between different types of the amblyopia differ from one type to another. The age could be considered as a predictor of the disease worsening and treatment prognosis. Further studies are required to emphasize these results.

Keywords: amblyopia, strabismus, anisometropia, optical coherence tomography

\section{Introduction}

Amblyopia is known as unilateral- or bilateral-reduced best-corrected visual acuity (BCVA) in response to abnormal visual stimulus throughout a critical period of development of the visual areas in the brain. Yet, some studies found a strong association between the amblyopic eye and cellular atrophy in the lateral geniculate nucleus (LGB).${ }^{1-3}$ Modern advances in neuroanatomy and neurophysiology have reopened the possibility that there is some retinal dysfunction in amblyopia. ${ }^{4}$ The retina is considered a motivating region for studying amblyopia and is still under investigation. The retinal alteration in the amblyopic eyes has not been clarified yet. ${ }^{5}$ Amblyopia might affect the postnatal maturation process of the retinal ganglion cells (RGCs), resulting in $\mathrm{RGC}$ reduction and abnormalities. ${ }^{6}$ 
Optical coherence tomography (OCT) is a noncontact and non-invasive high-resolution imaging technology of the retinal layers. ${ }^{7}$ There have been various attempts to investigate the structural changes in the macula and retinal nerve fiber layer (RNFL) of amblyopic eyes. ${ }^{8,9}$

So far, the study of macular and RNFL variations in amblyopic eyes is still an interesting research topic due to the diverse published results ${ }^{10-14}$ and the lack of evident association between these changes and the patients' parameters. Hence, this study was aimed to compare the variations in macular parameters (central thickness, average thickness, macular volume) and parapapillary RNFL thickness (RNFLT) in different cases of Egyptian amblyopic eyes versus the normal fellow eyes using spectral-domain OCT. In addition, it aimed to estimate the relationship of OCT variations with different defined patients' parameters (age, sex, BCVA, spherical equivalent [SE] refractive error, and axial length $[\mathrm{AL}])$.

\section{Patients and methods}

The study was designed as a prospective, observational, cross-sectional study, which was conducted from April 2013 to April 2014 at the Mansoura Ophthalmic Center, Mansoura University, Egypt.

\section{Ethical consideration}

The study was registered and reviewed by the ethics committee of Faculty of Medicine, Mansoura University. Approval from the Institutional Review Board was obtained and the study adhered to the Declaration of Helsinki (institutional review board [IRB]: R/16.10.41). Written informed consents were obtained from all patients or their parents after the nature of the study was well discussed.

\section{Subjects}

\section{Inclusion and exclusion criteria}

All cooperating patients with unilateral moderate amblyopia (visual acuity [VA] ranged from 0.3 to 0.1 ) and strabismic, anisometropic, and deprivational amblyopia with central fixation were included. Uncooperative patients, mixed amblyopia patients, patients with severe amblyopia with poor or eccentric fixation (VA $<0.1$ ), mentally retarded patients, and patients with any structural abnormalities of the eye, either congenital or acquired, were excluded.

\section{Methodology}

All enrolled patients underwent a complete history taking, including ocular history, general history, and family history; a comprehensive eye examination was performed, including slit lamp examination, cover test, prism bar cover test, assessment of ocular movements, and fundus examination using indirect ophthalmoscope. Cycloplegic autorefraction was determined by Canon auto refractometer (Canon CR-30; Canon, Inc., Huntington, NY, USA) and then assured by cycloplegic retinoscopy. Errors of refraction were converted into the SE. The SE was elucidated as the algebraic sum of spherical power plus half of the cylinder power in diopter (D). Monocular distance VA was tested (uncorrected and BCVA) using a Snellen chart and then converted into a decimal notation. The VA was tested by the single symbol presentation. Unfortunately, there were no facilities to use amblyopia VA charts. All patients tested by the same chart and in the same situation. Amblyopia was defined as BCVA $<20 / 40$ or $6 / 12$ in the affected eye, not attributed to any underlying structural abnormality of the eye or visual pathway, together with two or more lines on Snellen chart difference between the two eyes. Anisometropic amblyopia was assigned as the cause if there was at least $\geq 1.0 \mathrm{D}$ hyperopic difference in SE refraction between the two eyes in the absence of strabismus, $\geq 3.0$ D myopic difference in SE refraction between the two eyes in the absence of strabismus or $\geq 1.5 \mathrm{D}$ astigmatic difference in SE refraction between the two eyes in the absence of strabismus. Strabismic amblyopia was assigned as the cause if heterotropia was present or there was a history of previous strabismus surgery without anisometropia. Stimulus deprivation amblyopia was assigned as the cause if congenital cataract, ptosis, corneal opacities, or other media opacities obstructed vision. Mixed amblyopia was assigned as the cause, if any, of preceding causes, were present in combination. ${ }^{15}$

Macular imaging was accomplished with an OCT device (Topcon 3D-1000 Mark II; Topcon Medical Systems, Inc., Oakland, NJ, USA). A cube $6 \mathrm{~mm} \times 6 \mathrm{~mm}$ in length fixed on the macular area was scanned with a resolution of $128-512 \mu \mathrm{m}$. Pupillary dilation to a diameter of at least $5 \mu \mathrm{m}$ was done before the scanning. Internal fixation was used for all patients. Foveal fixation was assured by observing the retina via the infrared monitoring camera. The highdensity type with a typical $2 \mu \mathrm{m}$ deep and $6 \mu \mathrm{m}$ wide image was performed for macular scans. A $6 \mu \mathrm{m}$ macular thickness map centered on the foveola that divided the macula into nine regions was used (Figure 1). ${ }^{16}$ The quantitative assessment was performed by the use of the color-coded graph and the numerical map. The $6 \mu \mathrm{m}$ ring was divided into three rings, with the central ring corresponding to the fovea ( $1 \mu \mathrm{m}$ diameter), the middle ring corresponding to the 
A

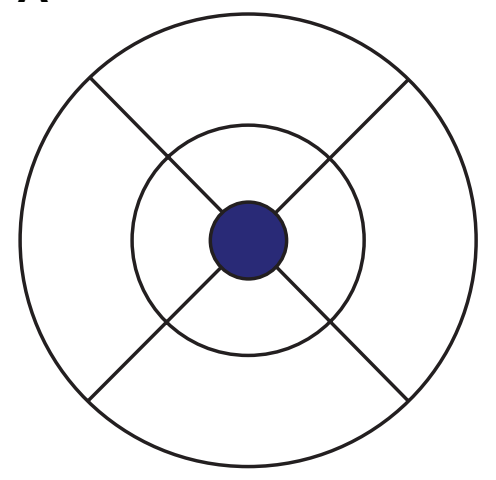

B

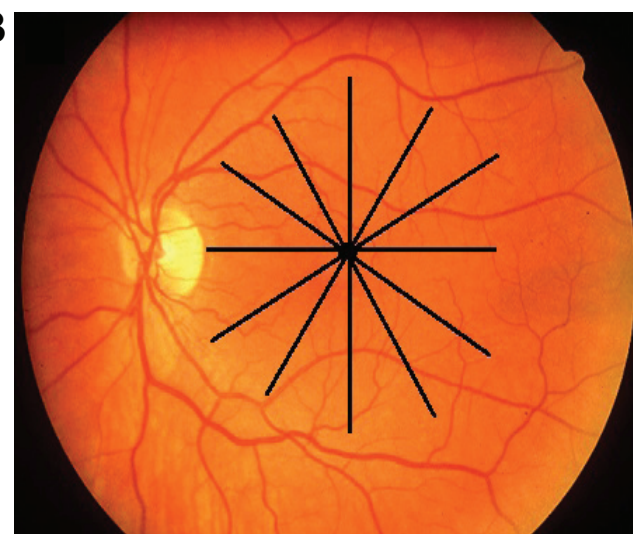

Figure I (A) The macular diameter map in $\mathrm{mm}$ with 9 regions centered around the foveal thickness (blue circle). (B) The macula with six radial lines centered on the fovea, each line equally oriented from the other (30 degrees between).

perifovea ( $2 \mu \mathrm{m}$ diameter), and the outer ring corresponding to the parafovea ( $3 \mu \mathrm{m}$ diameter; Figure 2). Central macular thickness (CMT; foveal thickness) was defined as the average macular thickness in the central $1 \mu \mathrm{m},{ }^{16,17}$ average macular thickness was defined as the mean of thicknesses in nine regions, ${ }^{18}$ and macular volume was defined as the sum of volumes in all nine regions. RNFLT was scanned with a diameter of $3.4 \mu \mathrm{m}$ around the optic disk. The software measured the mean thickness values for each quadrant (superior, inferior, temporal, and nasal) and the average global thickness of RNFL. The scanning was done on the normal eye first and then repeated on the amblyopic eye in the same visit. To ensure more accuracy, all the OCT scans were taken by the second author. Well-focused and good-quality scans

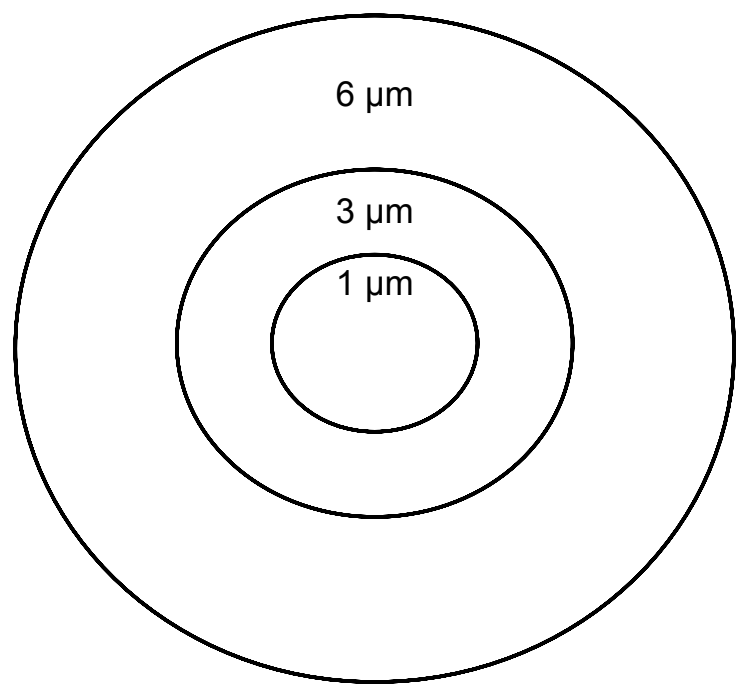

Figure 2 Schematic illustration of the macular map showing three concentric rings, with the central ring corresponding to the fovea ( $1 \mu \mathrm{m}$ diameter), the middle ring corresponding to the perifovea ( $2 \mu \mathrm{m}$ diameter), and the outer ring corresponding to the parafovea ( $3 \mu \mathrm{m}$ diameter). with a signal strength of $>20$ were only included, and poor quality or decentered scans were excluded.

The AL was measured by a Nidek's ultrasound device (Nidek US-4000; Nidek Medical Products, Inc., Fremont, CA, USA). Three readings were taken, and the average AL was calculated in micrometers $(\mu \mathrm{m})$ and used as an actual initial AL.

\section{Data collection}

BCVA, AL, SE, CMT, average macular thickness, macular volume, and RNFLT in different quadrants were collected from the amblyopic eyes and the fellow eyes as well as the age and the sex of all participants were collected.

\section{Statistical analysis}

Statistical analysis was performed using SPSS program version 20 (IBM Corporation, Armonk, NY, USA). All variables were displayed in mean \pm standard deviation. A paired $t$-test (two-tailed) was conducted to compare the mean of study outcomes between the amblyopic eyes and the other fellow eyes. The association between the macular parameters and RNFLT and the defined patients' parameters (age, sex, BCVA, AL, SE) was estimated by the linear regression test. To adjust the effect of SE on AL, the correlation using linear regression test between AL and SE was performed with a predicting equation to get "adjusted AL". The normality of study variables was tested by the histograms and $\mathrm{P}-\mathrm{P}$ plots. The $P$-value of $\leq 0.05$ was considered as statistically significant.

\section{Results}

\section{Demographic data and grouping of the patients}

A total of 64 patients were included whose age ranged between 7 and 32 years. The mean age was $13.3 \pm 3.7$ years. 
Table I Demographic data of the patients

\begin{tabular}{ll}
\hline Demographic & $\mathbf{N}=\mathbf{6 4}$ \\
\hline Sex & 35 females \\
& 29 males \\
Age, range (mean \pm SD), years & $7-32$ (I $3.3 \pm 3.7)$ \\
Types of amblyopia & Strabismic (22 cases) \\
& Visual deprivation ( 12 cases) \\
& Anisometropic (30 cases) \\
& - Myopic anisometropia (I0 cases) \\
& - Hyperopic anisometropia (14 cases) \\
& $\bullet$ Anisometropic astigmatism (6 cases) \\
\hline
\end{tabular}

In all, 35 patients were females and 29 were males. The patients were classified into three main groups: strabismic amblyopia (22 patients), anisometropic amblyopia (30 patients), and deprivation amblyopia (12 patients). The anisometropic group was subdivided into three subgroups: myopic anisometropia (10 patients), hyperopic anisometropia (14 patients), and astigmatic anisometropia (six patients; Table 1).

\section{Comparison of the mean macular thickness and RNFLT in amblyopic eyes versus the normal eyes}

The mean macular thickness (central thickness, average thickness, and macular volume) and the mean RNFLT in all patients versus the fellow eyes are presented in Table 2 . There was a statistically significant difference between the amblyopic eyes and the fellow eyes $(P<0.05)$. Figures 3 and 4 represent the differences between the amblyopic and fellow eyes.

\section{Parameters of strabismus amblyopic group}

Regarding the strabismus group, the mean BCVA was $0.3 \pm 0.1$ and the mean SE was $+0.5 \pm 0.75 \mathrm{D}$. In the strabismus group, there was a predominance of esotropia (18 cases)

Table 2 Mean macular thickness and the mean parapapillary RNFLT in all groups

\begin{tabular}{|c|c|c|c|}
\hline Parameters & $\begin{array}{l}\text { Amblyopic } \\
\text { eye }(n=64)\end{array}$ & $\begin{array}{l}\text { Fellow eye } \\
(n=64)\end{array}$ & $P$-value \\
\hline $\mathrm{CMT}, \mu \mathrm{m}$ & $196.2 \pm 50.03$ & $167 \pm 12.76$ & $0.000 *$ \\
\hline Average macular thickness & $265.80 \pm 12.77$ & $259.10 \pm 3.09$ & $0.000 *$ \\
\hline Macular volume, $\mathrm{mm}^{3}$ & $7.59 \pm 0.32$ & $7.34 \pm 0.07 \mid$ & $0.002^{*}$ \\
\hline \multicolumn{4}{|l|}{$\mathrm{RNFLT}, \mu \mathrm{m}$} \\
\hline Superior & $115 \pm 26.34$ & $107 \pm 21.38$ & $0.035^{*}$ \\
\hline Inferior & $121.20 \pm 19.27$ & $110.60 \pm 22.68$ & $0.048^{*}$ \\
\hline Temporal & $68.1 \pm 9.27$ & $67.8 \pm 11.02$ & 0.118 \\
\hline Nasal & $83.3 \pm 11.12$ & $78.4 \pm|2.3|$ & $0.044^{*}$ \\
\hline Total & $97.00 \pm 11.60$ & $78.50 \pm 13.05$ & $0.029 *$ \\
\hline
\end{tabular}

Notes: Test used: paired $t$-test (two tailed). *Significant at $<0.05$.

Abbreviations: RNFLT, retinal nerve fiber layer thickness; CMT, central macular thickness.

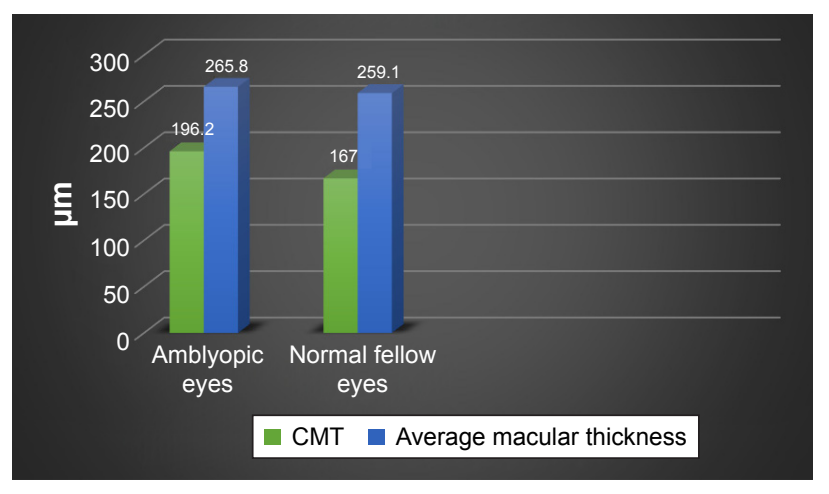

Figure 3 Mean macular thickness in the amblyopic eyes and the fellow normal eyes. There was a significant higher thickness in amblyopic eyes. Abbreviation: CMT, central macular thickness.

versus exotropia (four cases). The mean CMT and macular volume among this group were significantly higher than those of the fellow eyes ( $P=0.033$ and $P=0.047$, respectively), while the average macular thickness showed an insignificant increase in amblyopic eyes $(P=0.084)$. In addition, there was a significant difference in the global RNFLT values (Table 3).

\section{Parameters of deprivational amblyopic group}

Among the deprivational group, the mean BCVA was $0.1 \pm 0.1$ and the mean SE was $+1.0 \pm 0.6 \mathrm{D}$. The cases of deprivational amblyopia (12 patients) were as follows; nine cases had unilateral congenital cataract; they were operated after 2 years of age. There were three cases with severe ptosis (two cases were congenital and one case with posttraumatic third nerve palsy). The mean CMT showed a significant variance between the amblyopic eyes and the fellow eyes $(P=0.021)$, while the average macular thickness, macular volume, and the global RNFLT showed an insignificant difference (Table 4).

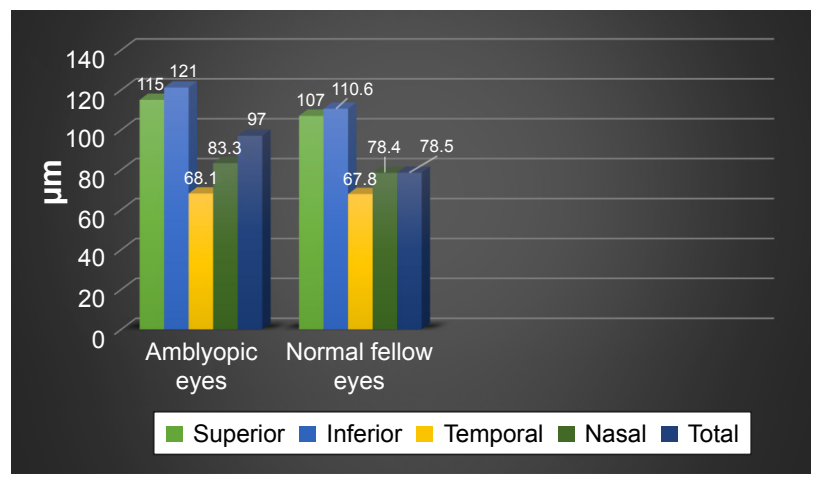

Figure 4 The difference in RNFLT in both amblyopic eyes and the normal fellow eyes. Abbreviation: RNFLT, retinal nerve fiber layer thickness. 
Table 3 Parameters in the strabismic amblyopic group

\begin{tabular}{llll}
\hline Parameters & $\begin{array}{l}\text { Amblyopic } \\
\text { eye }(\mathbf{n = 2 2})\end{array}$ & $\begin{array}{l}\text { Fellow eye } \\
(\mathbf{n = 2 2})\end{array}$ & P-value \\
\hline BCVA, decimal & $0.3 \pm 0.1$ & $0.9 \pm 0.11$ & $0.000^{*}$ \\
SE, Diopter & $+0.5 \pm 0.75$ & $+0.25 \pm 0.12$ & 0.125 \\
CMT, $\mu \mathrm{m}$ & $184 \pm 7.78$ & $181 \pm 3.65$ & $0.033^{*}$ \\
Average macular thickness & $262.8 \pm 7.63$ & $262.4 \pm 3.32$ & 0.084 \\
Macular volume, mm & $7.55 \pm 1.2$ & $7.41 \pm 1.1$ & $0.047^{*}$ \\
Parapapillary RNFLT, $\mu \mathrm{m}$ & & & \\
$\quad$ Superior & $117 \pm 7.24$ & $115 \pm 1.34$ & $0.010^{*}$ \\
$\quad$ Inferior & $139 \pm 10.25$ & $134 \pm 1.45$ & $0.000^{*}$ \\
$\quad$ Temporal & $70.2 \pm 9.25$ & $70 \pm 10.05$ & 0.945 \\
$\quad$ Nasal & $82 \pm 9.25$ & $81.8 \pm 10.05$ & $0.07 \mathrm{I}$ \\
$\quad$ Total & $105 \pm 9.22$ & $104 \pm 8.23$ & $0.02 I^{*}$ \\
\hline
\end{tabular}

Notes: Test used: paired $t$-test (two tailed). *Significant at $P<0.05$. Data presented as mean $\pm S D$.

Abbreviations: BCVA, best-corrected visual acuity; SE, spherical equivalent; CMT, central macular thickness; RNFLT, retinal nerve fiber layer thickness.

\section{Parameters of anisometropic amblyopic group}

In the anisometropic group, the mean BCVA was $0.2 \pm 0.01$, $0.1 \pm 0.02$, and $0.1 \pm 0.01$ in myopic, hyperopic, and astigmatic anisometropic subgroups, respectively. The mean SE in the previous three subgroups (myopic, hyperopic, and astigmatic) was $-8.0 \pm 2.0 \mathrm{D},+3.0 \pm 1.0 \mathrm{D}$, and $+2.0 \pm 1.0 \mathrm{D}$, respectively (Table 5).

In the myopic anisometropic subgroup, only the mean CMT was significantly higher in the amblyopic eyes, while the other macular values and the global RNFLT showed nonsignificant differences. In the hypermetropic anisometropic subgroup, there was a significant variation in all macular values and the global RNFLT in amblyopic eyes comparing with those in the fellow normal eyes. Lastly, in the astigmatic anisometropic subgroup, the mean CMT reported a significant increase, while there was not a significant difference

Table 4 Parameters in the visual deprivational amblyopic group

\begin{tabular}{|c|c|c|c|}
\hline Parameters & $\begin{array}{l}\text { Amblyopic } \\
\text { eye }(n=12)\end{array}$ & $\begin{array}{l}\text { Fellow eye } \\
(n=12)\end{array}$ & $P$-value \\
\hline BCVA, decimal & $0.1 \pm 0.1$ & $0.84 \pm 0.1$ & $0.001 *$ \\
\hline SE, Diopter & $+1.0 \pm 0.6$ & $+5.0 \pm 0.25$ & $0.000^{*}$ \\
\hline $\mathrm{CMT}, \mu \mathrm{m}$ & $170 \pm 2.25$ & $165 \pm 1.78$ & $0.021 *$ \\
\hline Average macular thickness & $255 \pm 2.22$ & $255.7 \pm 2.22$ & 0.721 \\
\hline Macular volume, $\mathrm{mm}^{3}$ & $7.43 \pm 1.2$ & $7.35 \pm 1.2$ & 0.076 \\
\hline \multicolumn{4}{|l|}{ Parapapillary RNFLT, $\mu \mathrm{m}$} \\
\hline Superior & $127 \pm 7.04$ & $115 \pm 8.23$ & $0.01 *$ \\
\hline Inferior & $126 \pm 9.23$ & $115 \pm 9.23$ & $0.01 *$ \\
\hline Temporal & $72.3 \pm 8.15$ & $72 \pm 8.15$ & 0.782 \\
\hline Nasal & $84.4 \pm 7.15$ & $83.4 \pm 9.11$ & 0.142 \\
\hline Total & $103 \pm 8.23$ & $102 \pm 8.23$ & 0.214 \\
\hline
\end{tabular}

Notes: Test used: paired $t$-test (two tailed). *Significant at $P<0.05$.

Abbreviations: BCVA, best-corrected visual acuity; SE, spherical equivalent; CMT, central macular thickness; RNFLT, retinal nerve fiber layer thickness.
Table 5 Parameters in the anisometropic amblyopic group

\begin{tabular}{|c|c|c|c|}
\hline Parameters & Amblyopic eye & Fellow eye & $P$-value \\
\hline \multicolumn{4}{|l|}{ BCVA, decimal } \\
\hline Myopic & $0.2 \pm 0.01$ & $0.9 \pm 0.1$ & $0.000 *$ \\
\hline Hyperopic & $0.1 \pm 0.02$ & $\mathrm{I} .0 \pm 0.0 \mathrm{I}$ & $0.000 *$ \\
\hline Astigmatic & $0.1 \pm 0.01$ & $0.9 \pm 0.1$ & $0.000 *$ \\
\hline \multicolumn{4}{|l|}{ SE, Diopter } \\
\hline Myopic & $-8.0 \pm 2.0$ & $-2.0 \pm 1.0$ & $0.000 *$ \\
\hline Hyperopic & $+3.0 \pm 1.0$ & $+0.5 \pm 0.5$ & $0.00 I^{*}$ \\
\hline Astigmatic & $+2.0 \pm 1.0$ & $+0.5 \pm 0.5$ & $0.001 *$ \\
\hline \multicolumn{4}{|l|}{ CMT, $\mu \mathrm{m}$} \\
\hline Myopic & $156 \pm 5.18$ & $150 \pm 3.55$ & $0.032^{*}$ \\
\hline Hyperopic & $289 \pm 9.78$ & $160 \pm 3.42$ & $0.000 *$ \\
\hline Astigmatic & $182 \pm 6.22$ & $118 \pm 2.11$ & $0.001 *$ \\
\hline \multicolumn{4}{|c|}{ Average macular thickness, $\mu \mathrm{m}$} \\
\hline Myopic & $255.6 \pm 6.11$ & $256 \pm 4.35$ & 0.092 \\
\hline Hyperopic & $288.2 \pm 7.05$ & $259 \pm 4.35$ & $0.00 I^{*}$ \\
\hline Astigmatic & $267.4 \pm 6.14$ & $262.4 \pm 3.15$ & $0.04 I^{*}$ \\
\hline \multicolumn{4}{|c|}{ Macular volume, $\mathrm{mm}^{3}$} \\
\hline Myopic & $7.23 \pm 1.2$ & $7.24 \pm 1.22$ & 0.951 \\
\hline Hyperopic & $8.15 \pm 1.32$ & $7.29 \pm 1.12$ & $0.00 I^{*}$ \\
\hline Astigmatic & $7.58 \pm 1.12$ & $7.4 I \pm 1.23$ & $0.03 I^{*}$ \\
\hline \multicolumn{4}{|c|}{ RNFLT, $\mu \mathrm{m}$ (superior) } \\
\hline Myopic & $127 \pm 6.04$ & $126 \pm 4.04$ & 0.924 \\
\hline Hyperopic & $140 \pm 5.23$ & $114 \pm 3.11$ & $0.001 *$ \\
\hline Astigmatic & $68 \pm 4.15$ & $68 \pm 3.24$ & I \\
\hline \multicolumn{4}{|c|}{ RNFLT, $\mu \mathrm{m}$ (inferior) } \\
\hline Myopic & $130 \pm 5.13$ & $114 \pm 4.22$ & $0.013 *$ \\
\hline Hyperopic & $125 \pm 5.04$ & $120 \pm 4.15$ & $0.035^{*}$ \\
\hline Astigmatic & $86 \pm 4.21$ & $70 \pm 2.24$ & $0.04 I^{*}$ \\
\hline \multicolumn{4}{|c|}{ RNFLT, $\mu \mathrm{m}$ (temporal) } \\
\hline Myopic & $85 \pm 3.11$ & $84 \pm 3.05$ & 0.957 \\
\hline Hyperopic & $86 \pm 3.22$ & $80 \pm 2.04$ & $0.001 *$ \\
\hline Astigmatic & $65 \pm 2.24$ & $64.7 \pm 1.87$ & I \\
\hline \multicolumn{4}{|l|}{ RNFLT (nasal) } \\
\hline Myopic & $82 \pm 4.11$ & $82 \pm 3.14$ & I \\
\hline Hyperopic & $78 \pm 3.04$ & $70 \pm 3.42$ & $0.025^{*}$ \\
\hline Astigmatic & $63 \pm 3.32$ & $62 \pm 3.24$ & 0.742 \\
\hline \multicolumn{4}{|c|}{ RNFLT, $\mu \mathrm{m}$ (total) } \\
\hline Myopic & $102 \pm 3.44$ & $99 \pm 2.14$ & 0.065 \\
\hline Hyperopic & $110 \pm 4.22$ & $102 \pm 2.77$ & $0.032 *$ \\
\hline Astigmatic & $64 \pm 3.01$ & $63 \pm 3.21$ & $0.84 I$ \\
\hline
\end{tabular}

Notes: Test used: paired $t$-test (two tailed). *Significant at $P<0.05$. Data presented as mean \pm SD.

Abbreviations: BCVA, best-corrected visual acuity; SE, spherical equivalent; CMT, central macular thickness; RNFLT, retinal nerve fiber layer thickness.

in the total RNFLT. All details of the measured values and their $P$-values are displayed in Table 5.

\section{Linear regression analysis}

Mean $A L$ and the effect of SE

Linear regression analysis performed between $\mathrm{AL}$ and $\mathrm{SE}$ showed a significant correlation $(P=0.000, B=0.489$, adjusted $R^{2}=0.227,95 \%$ confidence interval $\left.[\mathrm{CI}]=0.173-0.460\right)$. The linear regression model was displayed by the equation $\mathrm{AL}$ (adjusted) $=21.626+0.316(\mathrm{SE})$. The mean adjusted AL was $22.36 \pm 1.79$ (Figure 5). 
AL

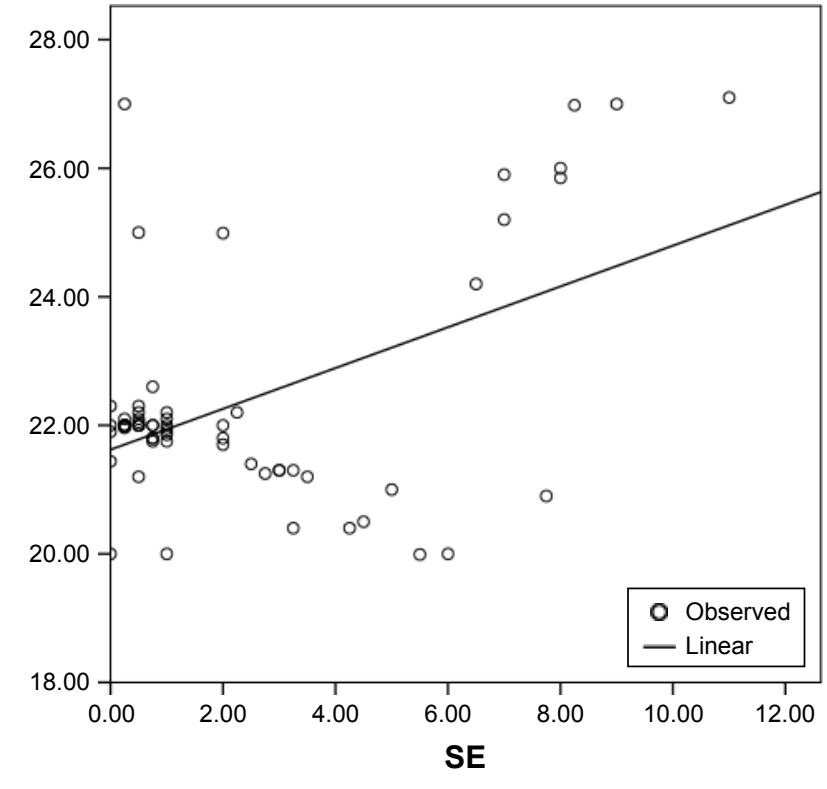

Figure 5 Correlation of initial $\mathrm{AL}$ and $\mathrm{SE}$ with $95 \% \mathrm{Cl}$ of the regression line. $P=0.000$, $B=0.489$, adjusted $R^{2}=0.227,95 \% \mathrm{Cl}=0.173-0.460$. The linear regression model: $\mathrm{AL}$ (adjusted) $=21.626+0.316(\mathrm{SE})$.

Abbreviations: $\mathrm{AL}$, axial length; $\mathrm{SE}$, spherical equivalent; $\mathrm{Cl}$, confidence interval.

Linear regression between the OCT findings and the previously defined patients' parameters

The details are shown in Table 6. The age and the initial $\mathrm{AL}$ were the only independent variables that statistically significantly correlated to the CMT. The age was positively correlated to the CMT in amblyopic eyes $(P=0.002, B=0.831$, adjusted $R^{2}=0.686,95 \% \mathrm{CI}=4.701-6.624$; Figure 6$)$. The initial AL was negatively correlated to the CMT $(P=0.016$, $B=-0.301$, adjusted $R^{2}=0.191,95 \%$ CI $=-1.050-1.634$; Figure 7), while after adjustment of AL, linear regression between the adjusted AL and CMT in amblyopic eyes showed an insignificant correlation $(P=0.930, B=0.011$, adjusted $R^{2}=0.016,95 \%$ CI $=-13.82-15.10$; Figure 8 ). The linear regression analysis between the age and CMT in normal eyes showed an insignificant inverse relation $(P=0.073, B=-0.390$, adjusted $R^{2}=0.111,95 \% \mathrm{CI}=-1.44-0.070$; Figure 9).

\section{Discussion}

Amblyopia is known as a disease occurring during the development and maturation period of the visual pathway between the retina and the central neurons. It has various impacts on different neural levels of the visual pathway; however, the definite site of its influence is still under inquiry. ${ }^{19}$ Some investigators hypothesized that the alterations in the LGB neurons and the visual cortex might be the primary sites of the amblyopic impact. ${ }^{2,3}$ With advances in imaging technology, interest has emerged to study the differences in the retinal structure in amblyopia. ${ }^{20,21}$

In the current study, there was a significant difference in both macular thickness and global RNFLT between the amblyopic eye and the other normal fellow eye. Furthermore,

Table 6 Correlations between the OCT findings and patients' parameters in amblyopic eyes

\begin{tabular}{|c|c|c|c|c|c|c|}
\hline $\begin{array}{l}\text { Amblyopic eyes } \\
\text { parameters }\end{array}$ & Age & Sex & BCVA & SE (D) & $\begin{array}{l}\text { Initial AL } \\
(\mu \mathrm{m})\end{array}$ & $\begin{array}{l}\text { Adjusted AL } \\
(\mu \mathrm{m})\end{array}$ \\
\hline \multicolumn{7}{|l|}{ CMT } \\
\hline$P$-value & $0.002 *$ & 0.593 & 0.687 & 0.915 & $0.016 *$ & 0.93 \\
\hline$B$ coefficient & 0.831 & -0.068 & 0.051 & 0.014 & -0.301 & 0.011 \\
\hline Adjusted $R^{2}$ value & 0.686 & 0.011 & 0.013 & 0 & 0.191 & 0.016 \\
\hline $95 \% \mathrm{Cl}$ & $4.70 \mathrm{I}-6.624$ & $-1.44-6.595$ & $-27.20-13.484$ & $-4.306-4.79 \mid$ & $-1.050-1.634$ & $-13.82-15.10$ \\
\hline \multicolumn{7}{|c|}{ Average macular thickness } \\
\hline$P$-value & 0.335 & 0.457 & 0.65 & 0.798 & 0.924 & 0.785 \\
\hline B coefficient & 0.123 & 0.095 & 0.003 & 0.033 & -0.012 & -0.035 \\
\hline Adjusted $R^{2}$ value & -0.001 & 0.007 & 0.058 & 0.001 & 0 & 0.015 \\
\hline $95 \% \mathrm{Cl}$ & $-0.213-0.616$ & $-2.98-1.360$ & $-51.08-32.096$ & $-1.239-0.956$ & $-1.78-1.64$ & $-3.97-3.01$ \\
\hline \multicolumn{7}{|l|}{ Macular volume } \\
\hline$P$-value & $0.001 *$ & 0.448 & 0.781 & 0.668 & 0.481 & 0.666 \\
\hline$B$ coefficient & 0.574 & 0.096 & 0.035 & 0.055 & -0.09 & 0.055 \\
\hline Adjusted $R^{2}$ value & 0.319 & -7 & 0.001 & 0.003 & 0.008 & 0.013 \\
\hline $95 \% \mathrm{Cl}$ & $0.015-0.033$ & $-0.077-0.034$ & $-1.219-0.921$ & $-0.022-0.055$ & $-0.059-0.028$ & $-0.070-0.109$ \\
\hline \multicolumn{7}{|l|}{ Parapapillary RNFLT } \\
\hline$P$-value & 0.142 & 0.536 & 0.888 & 0.124 & 0.712 & 0.146 \\
\hline B coefficient & 0.185 & 0.079 & 0 & 0.194 & 0.047 & 0.184 \\
\hline Adjusted $R^{2}$ value & 0.019 & 0.01 & 0.018 & 0.038 & 0.002 & 0.018 \\
\hline $95 \% \mathrm{Cl}$ & $-0.17 \mid-1.164$ & $2.102-4.003$ & $-5.313-6.589$ & $-0.334-2.689$ & $-1.939-2.82 \mid$ & $-1.27-8.36$ \\
\hline
\end{tabular}

Notes: Test used: linear regression. *Significant at $P<0.05$.

Abbreviations: OCT, optical coherence tomography; BCVA, best-corrected visual acuity; SE, spherical equivalent; D, diopter; AL, axial length; CMT, central macular thickness; $\mathrm{Cl}$, confidence interval; RNFLT, retinal nerve fiber layer thickness. 


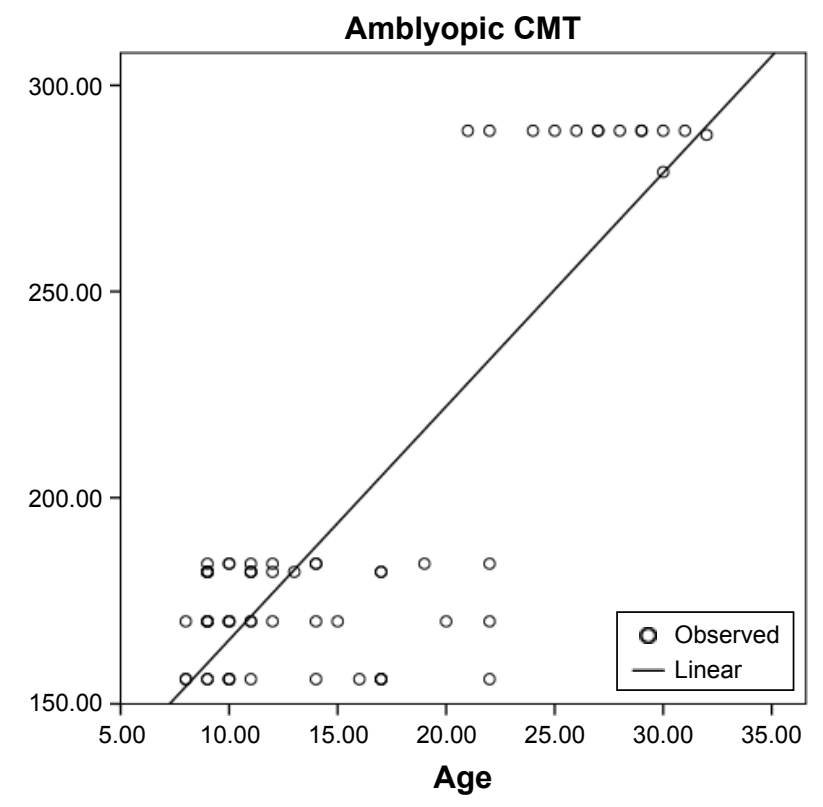

Figure 6 Correlation of the age and CMT in amblyopic eyes with $95 \% \mathrm{Cl}$ of the regression line $\left(P=0.002, B=0.83 \mathrm{I}\right.$, adjusted $\left.R^{2}=0.686,95 \% \mathrm{Cl}=4.70 \mathrm{I}-6.624\right)$.

Abbreviations: $\mathrm{CMT}$, central macular thickness; $\mathrm{Cl}$, confidence interval.

we found a strong positive correlation between the patient's age and changes in CMT in the amblyopic eyes, while in the normal fellow eyes, there was an insignificant inverse correlation. In addition, the initial AL (without adjustment) was significantly inversely correlated with CMT, but after adjustment, this correlation faded.

The retinal involvement in the amblyopic process is up till now controversial. ${ }^{3}$ Diverse experimental studies have

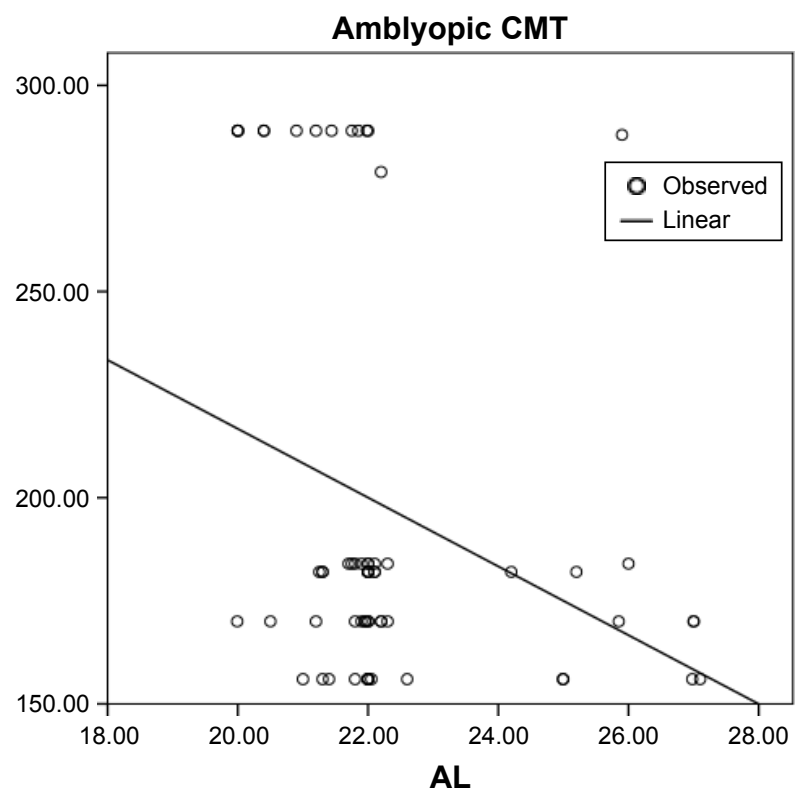

Figure 7 Correlation of the initial $\mathrm{AL}$ and $\mathrm{CMT}$ in amblyopic eyes with $95 \% \mathrm{Cl}$ of the regression line $\left(P=0.016, B=-0.30 \mathrm{I}\right.$, adjusted $\left.R^{2}=0.191,95 \% \mathrm{Cl}=-1.050-1.634\right)$. Abbreviations: $\mathrm{AL}$, axial length; $\mathrm{CMT}$, central macular thickness; $\mathrm{Cl}$, confidence interval.

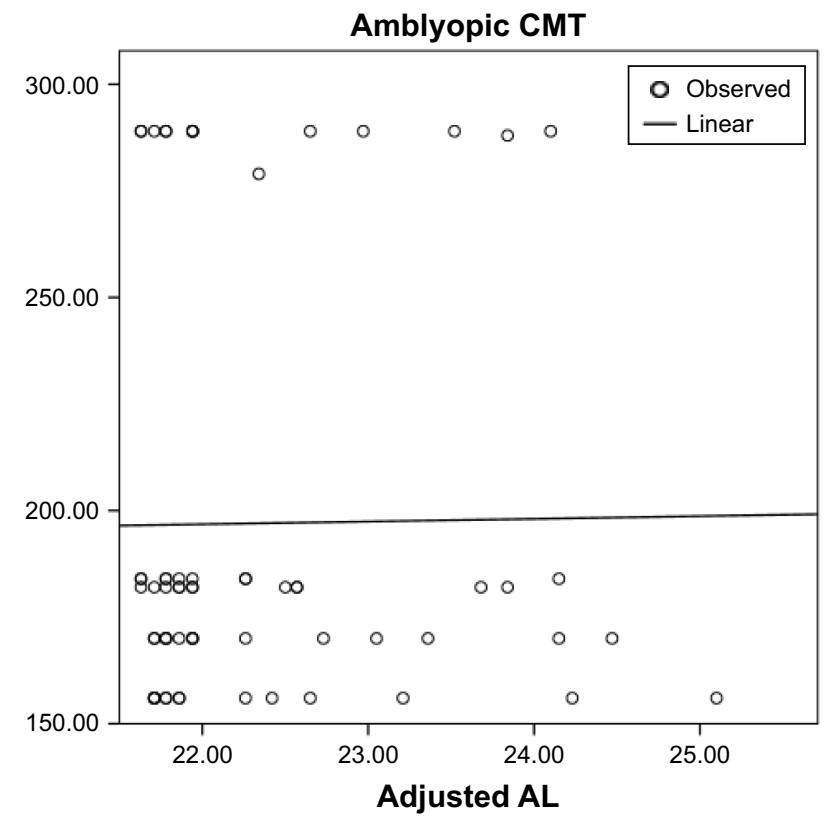

Figure 8 Correlation of the adjusted $\mathrm{AL}$ and CMT in amblyopic eyes with $95 \% \mathrm{Cl}$ of the regression line $\left(P=0.930, B=0.01 \mathrm{I}\right.$, adjusted $\left.R^{2}=0.016,95 \% \mathrm{Cl}=-\mid 3.82-15.10\right)$. Abbreviations: $\mathrm{AL}$, axial length; $\mathrm{CMT}$, central macular thickness; $\mathrm{Cl}$, confidence interval.

revealed retinal microstructures changes in amblyopic eyes such as degradation of $\mathrm{RGCs},{ }^{22}$ a decline in the nucleolar volume in the cytoplasmic area of RGCs, ${ }^{23}$ thinning in the internal plexiform layer with a decreased number of the bipolar synapses ${ }^{24}$ and a reduction in the density of Müller fibers. ${ }^{25}$

Regarding the electroretinogram (ERG) evaluation of the human amblyopic eye, there was a remarkable reduction

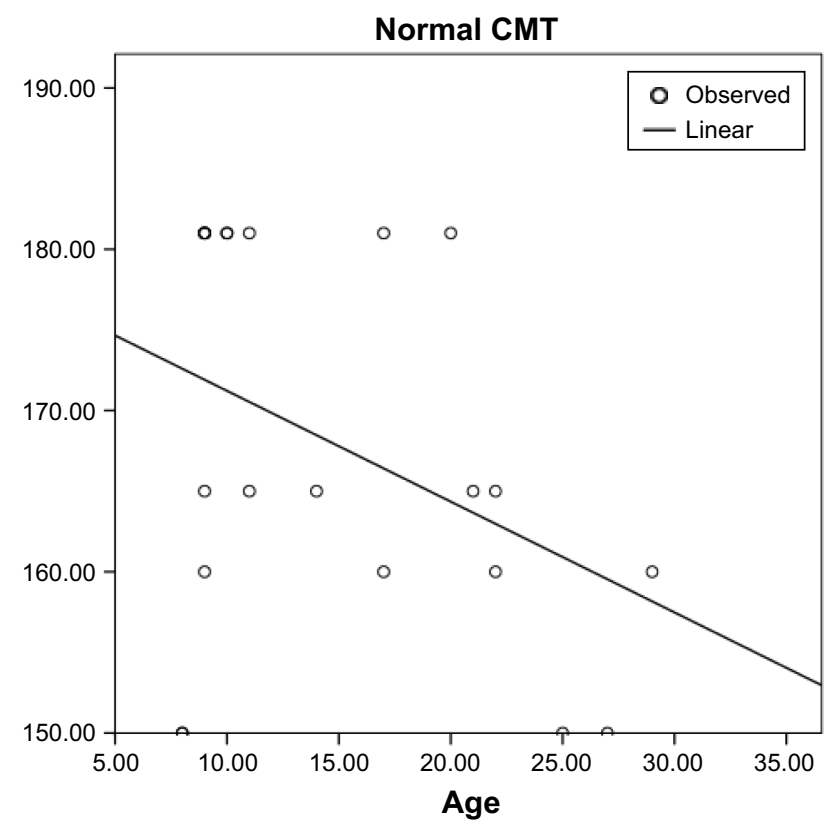

Figure 9 Correlation of the age and CMT in normal fellow eyes with $95 \% \mathrm{Cl}$ of the regression line $\left(P=0.073, B=-0.390\right.$, adjusted $\left.R^{2}=0.111,95 \% \mathrm{Cl}=-1.44-0.070\right)$. Abbreviations: $\mathrm{CMT}$, central macular thickness; $\mathrm{Cl}$, confidence interval. 
and disturbed retinal response toward the pattern stimuli in the amblyopic eyes. ${ }^{26,27}$ This presumed and might support the amblyopic changes at the retinal level. On the contrary, others found insignificant changes in the pattern of ERG in the amblyopic eyes. ${ }^{28,29}$

Currently, the retinal changes in various unilateral amblyopic types were evaluated using the OCT scans. There was a significant increase in the macular thickness and macular volume in all amblyopic eyes comparing to the other fellow eyes. This corroborated with the previous studies, ${ }^{9,12}$ while other researchers reported no significant variations in the macular thickness ${ }^{10,30,31}$ or RNFLT ${ }^{10,11,30,31}$ in amblyopic eyes.

When comparing the foveal thickness in the strabismic amblyopic eyes, the current results reported higher values than the normal eyes, which emphasized those of previous studies. $^{20,32,33}$ In contrast, other studies found an insignificant difference between the amblyopic eyes and the normal eyes in the strabismic group. ${ }^{34,35}$ In addition, we observed that the same difference was found in the total RNFLT in this group (strabismic amblyopia), which was corresponding to other finding $\mathrm{s}^{20,35}$ and in contrast to others. ${ }^{34,36}$

The precise cause of the increased RNFLT in the amblyopia is unclear, but it may be due to the influence of the amblyopia on the retinal postnatal maturation with a decrease in the RGCs. This might produce an increase in the RNFLT measured via OCT. ${ }^{37}$ So, it supposedly stated that the postnatal changes would lead to a similar effect on the normal macular maturation as well, including Henle's fibers movement far away from the foveola with a reduction in the foveal diameter and an increase in the measurable foveal thickness. ${ }^{33}$ This assumption could explain some of the anatomic changes existing in the retina of the amblyopic eyes. ${ }^{37}$

Concerning the visual deprivational amblyopia, there were few studies that reported the changes in this type. Kim et $\mathrm{al}^{38}$ did not find a considerable variance in deprivational amblyopic eyes compared to the normal eyes regarding the macular thickness, while they found thicker nasal RNFL in the amblyopic eyes. The present results were in contrast to this finding: there was a significant increase in the foveal thickness and the superior and inferior RNFLT. This difference in the results may be due to the measuring of the eccentric parafoveal area accidentally rather than the central foveal area. ${ }^{39}$ This issue was of concern to the authors, and any patient with eccentric fixation was excluded from the study and the central foveal location was being confirmed during the macular scanning.

Numerous previous studies have dealt with the changes in anisometropic amblyopia with different results. ${ }^{40-43}$ In the present study, the hypermetropic amblyopic eyes exhibited a thicker CMT, thicker average macular thickness, and higher macular volume than the normal eyes. These findings are in agreement with the previous results of different studies, which formerly demonstrated a greater macular thickness in hypermetropic-affected eyes. ${ }^{14,40,41}$ In contrast to these results, other studies reported that the difference in the macular thickness between the hypermetropic amblyopic and the normal eyes was negligible. ${ }^{13,32,42,43}$ The same higher values regarding RNFLT were found in hypermetropic amblyopic eyes with a significant difference from the normal eyes. These results are parallel to some studies ${ }^{8,37,44}$ and contrast to the other ones. ${ }^{13,32,42,43}$

The current findings in myopic eyes were consistent with Pang et al. ${ }^{12}$ They reported a statistically significant higher CMT in the amblyopic eyes versus the normal fellow eyes. In addition, the RNFL values in the present study did not demonstrate a significant difference between the myopic amblyopia and the other normal eyes. Previous studies concluded the minimal influence of the myopia, mainly mild degrees on the macular thickness. ${ }^{45,46}$ However, further evaluation is needed to ascertain if the macular thickness changes are due to amblyopia, myopia, or both. The discrepancy between all the mentioned studies presumably is a consequence of diversity in the OCT devices, measurement inaccuracy, varied races, and different ages of the participants.

Currently, the main interesting finding is the relationship of age to the CMT changes. A positive significant linear relationship between the age and the macular thickness suggested that the greater the age, the higher the thickness of the macula and thus the increase in the amblyopia impacts. This means that the age could be considered as an independent factor of the disease worsening and a predictor of treatment prognosis that can help in the clinical implementation of amblyopia treatment modalities.

However, in the normal eyes, there was no such significant positive correlation between the age and the CMT as in amblyopic eyes. We could not demonstrate this correlation; on the contrary, there was a statistically insignificant inverse correlation.

There were contradictory results concerning age's relation to CMT changes in normal eyes; some reports were in agreement with the current findings showing no significant correlation, ${ }^{16,47}$ while others observed a significant correlation, either positive indicating an increase in the CMT with the age $\mathrm{e}^{48,49}$ or negative referring to a decrease in the CMT with the age. ${ }^{50,51}$

The current study reported a significant positive correlation between $\mathrm{AL}$ and SE. An inverse significant relation 
between the initial AL and CMT was found; however, the mean AL had no significant correlation with CMT in the linear correlation model when adjusted by SE. In other words, the SE of our study population had a significant effect on the AL. We thought that the adjustment of AL by SE might lead to statistically accurate results. This was in disagreement with Araki et al; ${ }^{52}$ they reported a significant correlation between the AL and CMT changes, which might be owing to the relatively small sample size (21 subjects with less difference in the mean SE among the study subjects). By contrast, Kok et a ${ }^{53}$ concluded consistent results with our findings; they did not find an abnormal relation between the AL and CMT in amblyopic eyes. We did not find a significant relationship between refractive errors and the macular thickness or macular volume. This might be due to the exclusion of extreme errors or severe amblyopia from the study. This was in agreement with the conclusions of Rajavi et al. ${ }^{54}$ However, to substantiate these results, a survey with a large sample size will be required including severe amblyopia.

The limitation of the present study was a relatively small sample size, whereas the broad age range (7-32 years), control group of the fellow eyes, and the correlation between the OCT parameters with different patients' characteristics, especially age and AL, were considered points of strength, which will further amend our assimilation in this area.

\section{Conclusion}

The eyes with unilateral amblyopia were prone to have a higher CMT and thicker global RNFL when compared to the normal fellow eyes. Retinal thickness variations between different types of the amblyopia differ from one type to another. Owing to our findings, the age appeared to be an independent factor of CMT variations in amblyopic eyes and has to be taken into consideration during the treatment course of the amblyopia. Further studies are needed to clarify and confirm these findings.

\section{Disclosure}

The authors report no conflicts of interest in this work.

\section{References}

1. Von Norden GK, Crawford ML. The lateral geniculate nucleus in human strabismic amblyopia. Invest Ophthalmol Vis Sci. 1992;33(9): 2729-2732.

2. Asper L, Crewther D, Crewthei SG. Strabismic amblyopia. Part 2. Neural processing. Clin Exp Optom. 2000;83(4):200-211.

3. Hess RF, Thompson B, Gole G, Mullen KT. Deficient responses from the lateral geniculate nucleus in humans with amblyopia. Eur J Neurosci. 2009;29(5):1064-1070.

4. Hess RF. Amblyopia: site unseen. Clin Exp Optom. 2001;84(6):321-336.
5. Firat PG, Ozsoy E, Demirel S, Cumurcu T, Gunduz A. Evaluation of peripapillary retinal nerve fiber layer, macula and ganglion cell thickness in amblyopia using spectral optical coherence tomography. Int J Ophthalmol. 2013;6(1):90-94.

6. Lempert P. Optic nerve hypoplasia and small eyes in presumed amblyopia. J AAPOS. 2000;4(5):258-266.

7. Hee MR, Izatt JA, Swanson EA, et al. Optical coherence tomography of the human retina. Arch Ophthalmol. 1995;113(3):325-332.

8. Yoon SW, Park WH, Baek SH, Kong SM. Thicknesses of macular retinal layer and peripapillary retinal nerve fiber layer in patients with hyperopic anisometropic amblyopia. Korean J Ophthalmol. 2005; 19(1):62-67.

9. Huynh SC, Samarawickrama C, Wang XY, et al. Macular and nerve fiber layer thickness in amblyopia: the Sydney Childhood Eye Study. Ophthalmology. 2009;116(9):1604-1609.

10. Kee SY, Lee SY, Lee YC. Thicknesses of the fovea and retinal nerve fiber layer in amblyopic and normal eyes in children. Korean $J$ Ophthalmol. 2006;20(3):177-181.

11. Repka MX, Kraker RT, Tamkins SM, et al. Retinal nerve fiber layer thickness in amblyopic eyes. Am J Ophthalmol. 2009;148(1):143-147.

12. Pang Y, Goodfellow GW, Allison C, Block S, Frantz KA. A prospective study of macular thickness in amblyopic children with unilateral high myopia. Invest Ophthalmol Vis Sci. 2011;52(5):2444-2449.

13. Tugcu B, Araz-Ersan B, Kilic M, Erdogan ET, Yigit U, Karamursel S. The morpho-functional evaluation of retina in amblyopia. Curr Eye Res. 2013;38(7):802-809.

14. Al-Haddad CE, El Mollayess GM, Mahfoud ZR, Jaafar DF, Bashshur ZF. Macular ultrastructural features in amblyopia using high-definition optical coherence tomography. Br J Ophthalmol. 2013;97(3):318-322.

15. Repka MX, Beck RW, Holmes JM, et al. A randomized trial of patching regimens for treatment of moderate amblyopia in children. Arch Ophthalmol. 2003;121(5):603-612.

16. Chan A, Duker JS, Ko TH, Fujimoto JG, Schuman JS. Normal macular thickness measurements in healthy eyes using stratus optical coherence tomography. Arch Ophthalmol. 2006;124(2):193-198.

17. Sull AC, Vuong LN, Price LL, et al. Comparison of spectral/Fourier domain optical coherence tomography instruments for assessment of normal macular thickness. Retina. 2010;30(2):235-245.

18. Faghihi H, Faghihi S, Ghassemi F, et al. Measurement of normal macular thickness using cirrus optical coherence tomography instrument in Iranian subjects with normal ocular condition. Iran J Ophthalmol. 2013;25(2):107-114.

19. Szigeti A, Tátrai E, Szamosi A, et al. A morphological study of retinal changes in unilateral amblyopia using optical coherence tomography image segmentation. PLoS One. 2014;9(2):e88363.

20. Dickmann A, Petroni S, Salerni A, Dell'Omo R, Balestrazzi E. Unilateral amblyopia: an optical coherence tomography study. J AAPOS. 2009;13(2):148-150.

21. Al-Haddad CE, Mollayess GM, Cherfan CG, Jaafar DF, Bashshur ZF. Retinal nerve fibre layer and macular thickness in amblyopia as measured by spectral-domain optical coherence tomography. Br J Ophthalmol. 2011;95(12):1696-1699.

22. Von Norden GL, Crawford ML, Middleditch PR. Effect of lid suture on retinal ganglion cells in Macacamulatta. Brain Res. 1977;122(3): 437-444.

23. Rasch E, Swift H, Riesen AH, Chow KL. Altered structure and composition of retinal cells in darkreared mammals. Exp Cell Res. 1961;25: 348-363.

24. Fifkova E. Effect of visual deprivation and light on synapses of the inner plexiform layer. Exp Neurol. 1972;35(3):458-469.

25. Weiskrantz L. Sensory deprivation and the cat's optic nervous system. Nature. 1958;181(4615):1047-1050.

26. Li JD. A pattern-ERG study of amblyopia. Zhonghua Yan Ke Za Zhi. 1989;25(3):138-140.

27. Dahlke C, Dodt E. Amblyopic eyes produce an abnormal electroretinogram in pattern presentation with the on-off technique. Ophthalmologe. 1994;91(2):176-180. 
28. Gottlob I, Welge-Lüssen L. Normal pattern electroretinograms in amblyopia. Invest Ophthalmol Vis Sci. 1987;28(1):187-191.

29. Deline PJ, Weissenbruch C, Berendschot TT, Norren DV. Photoreceptors function in unilateral amblyopia. Vision Res. 1998;38(4):613-617.

30. Walker RA, Rubab S, Voll AR, Erraguntla V, Murphy PH. Macular and peripapillary retinal nerve fibre layer thickness in adults with amblyopia. Can J Ophthalmol. 2011;46(5):425-427.

31. Yassin SA, Al-Tamimi ER, Al-Hassan S. Macular and retinal nerve fiber thickness in recovered and persistent amblyopia. Int Ophthalmol. 2015;35(6):833-842.

32. Dickmann A, Petroni S, Perrotta V, et al. A morpho-functional study of amblyopic eyes with the use of optical coherence tomography and microperimetry. J AAPOS. 2011;15(4):338-341.

33. Agrawal S, Singh V, Singhal V. Cross-sectional study of macular thickness variations in unilateral amblyopia. J Clin Ophthalmol Res. 2014;2(1):15-17.

34. Altintas O, Yüksel N, Ozkan B, Caglar Y. Thickness of the retinal nerve fiber layer, macular thickness, and macular volume in patients with strabismic amblyopia. J Pediatr Ophthalmol Strabismus. 2005; 42(4):216-221.

35. Alotaibi AG, Al Enazi B. Unilateral amblyopia: optical coherence tomography findings. Saudi J Ophthalmol. 2011;25(4):405-409.

36. Colen TP, de Faber JT, Lemij HG. Retinal nerve fiber layer thickness in human strabismic amblyopia. Binocul Vis Strabismus Q. 2000;15(2): 141-146.

37. Yen MY, Cheng CY, Wang AG. Retinal nerve fiber layer thickness in unilateral amblyopia. Invest Ophthalmol Vis Sci. 2004;45(7):2224-2230.

38. Kim YW, Kim SJ, Yu YS. Spectral-domain optical coherence tomography analysis in deprivational amblyopia: a pilot study with unilateral pediatric cataract patients. Graefes Arch Clin Exp Ophthalmol. 2013; 251(12):2811-2819.

39. Leone J, Koklanis K, Georgievski Z, Wilkinson R. Macular and retinal nerve fibre layer thickness in strabismus and anisometropic amblyopia. Binocul Vis Strabismus Q. 2008;23(4):227-234.

40. Andalib D, Javadzadeh A, Nabai R, Amizadeh Y. Macular and retinal nerve fiber layer thickness in unilateral anisometropic or strabismic amblyopia. J Pediatr Ophthalmol Strabismus. 2013;50(4):218-221.

41. Yalcin E, Balci O. Peripapillary retinal nerve fiber layer and foveal thickness in hypermetropic anisometropic amblyopia. Clin Ophthalmol. 2014;12(8):749-753.

42. Wang BZ, Taranath D. A comparison between the amblyopic eye and normal fellow eye ocular architecture in children with hyperopic anisometropic amblyopia. J AAPOS. 2012;16(5):428-430.
43. Yakar K, Kan E, Alan A, Alp MH, Ceylan T. Retinal nerve fibre layer and macular thicknesses in adults with hyperopic anisometropic amblyopia. J Ophthalmol. 2015;2015:946467.

44. Wu SQ, Zhu LW, Xu QB, Xu JL, Zhang Y. Macular and peripapillary retinal nerve fiber layer thickness in children with hyperopic anisometropic amblyopia. Int J Ophthalmol. 2013;6(1):85-89.

45. Wakitani Y, Sasoh M, Sugimoto M, Ito Y, Ido M, Uji Y. Macular thickness measurements in healthy subjects with different axial lengths using optical coherence tomography. Retina. 2003;23(2):177-182.

46. Wu PC, Chen YJ, Chen $\mathrm{CH}$, et al. Assessment of macular retinal thickness and volume in normal eyes and highly myopic eyes with third-generation optical coherence tomography. Eye (Lond). 2008;22(4): 551-555.

47. Manassakorn A, Chaidaroon W, Ausayakhun S, Aupapong S, Wattananikorn S. Normative database of retinal nerve fiber layer and macular retinal thickness in a Thai population. Jpn J Ophthalmol. 2008; 52(60):450-456.

48. Duan XR, Liang YB, Friedman DS, et al. Normal macular thickness measurements using optical coherence tomography in healthy eyes of adult Chinese persons: the Handan Eye Study. Ophthalmology. 2010; 117(8):1585-1594.

49. Hashemi H, Khabazkhoob M, Yekta A, Emamian MH, Nabovati P, Fotouhi A. The distribution of macular thickness and its determinants in a healthy population. Ophthalmic Epidemiol. 2017;23:1-9.

50. Song WK, Lee SC, Lee ES, et al. Macular thickness variations with sex, age, and axial length in healthy subjects: a spectral domain-optical coherence tomography study. Invest Ophthalmol Vis Sci. 2010;51(8): 3913-3918.

51. Wei WB, Xu L, Jonas JB, et al. Subfoveal choroidal thickness: the Beijing eye study. Ophthalmology. 2013;120(1):175-180.

52. Araki S, Miki A, Yamashita T, et al. A comparison between amblyopic and fellow eyes in unilateral amblyopia using spectral-domain optical coherence tomography. Clin Ophthalmol. 2014;8:2199-2207.

53. Kok PH, de Kinkelder R, Braaksma-Besselink YC, et al. Anomalous relation between axial length and retinal thickness in amblyopic children. J AAPOS. 2013;17(6):598-602.

54. Rajavi Z, Moghadasifar H, Feizi M, et al. Macular thickness and amblyopia. J Ophthalmic Vis Res. 2014;9(4):478-483.
Clinical Ophthalmology

\section{Publish your work in this journal}

Clinical Ophthalmology is an international, peer-reviewed journal covering all subspecialties within ophthalmology. Key topics include: Optometry; Visual science; Pharmacology and drug therapy in eye diseases; Basic Sciences; Primary and Secondary eye care; Patient Safety and Quality of Care Improvements. This journal is indexed on Submit your manuscript here: http://www.dovepress.com/clinical-ophthalmology-journal

\section{Dovepress}

PubMed Central and CAS, and is the official journal of The Society of Clinical Ophthalmology (SCO). The manuscript management system is completely online and includes a very quick and fair peer-review system, which is all easy to use. Visit http://www.dovepress.com/ testimonials.php to read real quotes from published authors. 